\title{
O ENSINO DE CIÊNCIAS E A APRENDIZAGEM SIGNIFICATIVA Reflexões Sobre uma Aula Prática com a Utilização de Insetos
}

\author{
Luiz Antiogenes ${ }^{1}$ \\ Andrea Velloso da Silveira Praça²
}

\begin{abstract}
RESUMO
O presente artigo objetiva aprofundar nossas reflexões sobre o conceito de aprendizagem significativa e levantar as possibilidades de mudança de nossa prática com os alunos da escola pública. Nossas inquietações sobre o ensino de ciências têm origem nas discussões e estudos teóricos sobre a aprendizagem significativa efetivados no PPGEC da Unigranrio. Trazemos para nossa reflexão o resultado do estudo realizado, com o apoio do livro didático e de exemplares vivos de grilos, com 139 alunos de quatro turmas do 8 ano do Ensino Fundamental de uma escola pública situada no espaço de uma antiga fazenda no município de Nilópolis - RJ. Os resultados possibilitaram ampliar e questionar nossa compreensão sobre aprendizagem significativa, avançarmos e questionarmos juntos aos professores da escola sobre a utilização do livro didático como única estratégia de ensino, proporcionando, internamente, no espaço da escola, a reflexão sobre o que seja ensinar e aprender e de que forma os professores podem utilizar, como estratégias, os recursos existentes na escola. $O$ entendimento de que 0 significado da aprendizagem está no sujeito e não nas estratégias abre novas possibilidades de pensar e repensar os argumentos que circulam no interior da escola.
\end{abstract}

Palavras-chave: Aprendizagem significativa. Ensino de ciências. Aprendizagem.

\section{THE TEACHING OF SCIENCES AND SIGNIFICANT LEARNING - REFLECTIONS ON A PRACTICAL LESSON WITH THE USE OF INSECTS}

\begin{abstract}
This discussion aims to deepen our reflections on the concept of meaningful learning and raise the possibilities of change in our practice with public school students. Our concerns about the science education has its origins in the discussions and theoretical studies about the significant learning effect in PPGEC of Unigranrio. We bring to our reflection is the result of the study, with the support of the textbook and live specimens of crickets, along with 139 students in four classes from 8th grade of elementary school to a public high school located within an ancient farm in the county of Nilópolis - RJ. It was possible to expand and challenge our understanding of meaningful learning, move and question together to school teachers to use the textbook as the only teaching strategy, enabled, internally, within the school, the reflection on what is teaching and learning and how teachers can use, such as strategies, existing resources at school. The understanding that the meaning of learning in the person and not in the strategies, opens up new possibilities and to think and to rethink the arguments that circulate inside the school.
\end{abstract}

Keywords: Meaningful learning. Science teaching. Learning.

RECEBIDO EM: 9/9/2017

REVISÕES REQUERIDAS EM: 6/12/2017

ACEITO EM: 24/5/2018

\footnotetext{
${ }^{1}$ Bacharel e licenciado em Ciências Físicas e Biológicas, especialista em Ensino de Ciências e Biologia (UFRJ). Especialista em Biologia Parasitária (FTESM). Mestrando em Ensino de Ciências e Matemática na Educação Básica. http://lattes.cnpq.br/5944342523138380. Orcid: https://orcid.org/0000-0001-6714-9107. lopype@gmail.com

${ }^{2}$ Graduada em Ciências Biológicas pela Universidade do Estado do Rio de Janeiro (UERJ). Mestre em Ciências Biológicas e Doutora em Ciências - área de concentração em Educação, Gestão e Difusão em Biociências (Universidade Federal do Rio de Janeiro - UFRJ). velloso.a@gmail.com
} 
Nunca se falou tanto em educação como hoje em dia. A quantidade de livros produzidos e traduzidos, de pesquisas, tratados, dicionários e textos sobre ensino/ aprendizagem impressiona. Não só isso, mas outras formas, portais, revistas especializadas, cursos, congressos e jornadas sobre temas educacionais. Isso tudo não nos deixa dúvidas de que todos finalmente concordam que na educação repousa toda a esperança para o futuro, para um crescimento sólido não só sobre a educação, e sim sobre uma nova educação (ANTUNES, 2002).

A nova forma de educação depende da inovação contínua pelas tecnologias (aquisição e desenvolvimento), bem como de um "novo trabalhador", com altas habilidades, com capacidade de ser adaptável e flexível, com independência e responsabilidade (DE ABREU, 2001). O ensino de ciências está intimamente ligado ao desenvolvimento científico de um país, de uma região ou do mundo. As diretrizes do ensino acompanham as orientações científicas, incluídas também na necessidade tecnológica (DELIZOICOV; ANGOTTI, 1991). Tal desenvolvimento na área do ensino de ciências nem sempre foi assim. As aulas práticas por si mesmas não garantem a aprendizagem dos alunos, conforme destaca Moreira (2002), argumentando que o significado da aprendizagem está no sujeito que aprende, não nos materiais.

Os conhecimentos de natureza científica e tecnológica são cada vez mais valorizados na sociedade atual, que tem como principal característica um permanente e rápido processo de transformação. Na formação de um cidadão crítico e participativo tais conhecimentos devem promover a ampliação de sua compreensão do mundo, preparando-o para ser agente de mudanças qualitativas. Nesse contexto, o ensino de Ciências Naturais constitui "espaço privilegiado em que as diferentes explicações sobre o mundo, os fenômenos da natureza e as transformações produzidas pelo homem podem ser expostos e comparados" (BRASIL, 1999).

Para isso, o desenvolvimento de atitudes e valores é tão essencial quanto o aprendizado de conceitos e de procedimentos. Nesse sentido, é responsabilidade da escola e do professor promoverem o questionamento, o debate, a investigação, visando ao entendimento da ciência como construção histórica e como saber prático, superando as limitações do ensino passivo, baseado na memorização de definições e de classificações sem qualquer sentido para o aluno (BRASIL, 1998)

No ensino acadêmico, assim como na Ciência, o conhecimento apoia-se em modelos para explicar fenômenos não ou parcialmente observáveis. Os modelos didáticos utilizados em sala de aula têm a função de facilitar a transposição dos modelos científicos consensuais para o contexto escolar (GILBERT; BOULTER, 1993). A adoção de modelos didáticos na prática pedagógica coloca os professores diante da necessidade de tornar 0 conhecimento científico aplicável ao cotidiano do aluno. Sabemos que existe uma grande dificuldade por parte dos docentes de transpor certos conteúdos devido à falta de recursos e principalmente pelo teor engessado apresentado nos livros didáticos. Como exemplo: os seres vivos, artrópodes, insetos, invertebrados, ecologia, transferência de matéria e energia, cadeias e teias alimentares, ciclo de vida, reprodução, classificação taxonômica, relações ecológicas, evolução, adaptação, entre outros. 
A transposição de conteúdos por meio da utilização de estratégias inovadoras no uso de recursos didáticos se apresenta-se como proposta facilitadora do processo de ensino-aprendizagem, buscando tornar as aulas mais cativantes e dinâmicas (MORAES, 2016). Segundo Matos et al. (2009), uma das grandes dificuldades encontradas pelos professores de Biologia é o planejamento e a organização do conteúdo a ser ensinado, de forma que esse seja mais bemelhor assimilado pelos educandos. CorroborandoEm comunhão, Predon e Del Pino (2009) destacamembasam ainda, que muitas dessas dificuldades vêm da própria formação de professor, pois não há muitos espaços nos cursos de Licenciaturas para a vivência em novas práticas, apesar de tê-las estudado. Com isso, percebe-se que a resistência em utilizar modelos e materiais didáticos origina-se, entre outros fatores, da insegurança em aplicá-los, medo de se desvincular-se do quadro e do giz.

Conforme Krapas et al. (1997), na literatura de educação em Ciências o termo modelo aparece com frequência, mas assume diversos sentidos. Sendo assim, é definido como uma articulação entre o conteúdo e metodologia, como também entre empiria e experimento, onde conteúdos e modelos se relacionam por meio de proposições ou imagens. Segundo o autor supracitado, esta articulação entre proposições e imagens nos leva a um conceito de modelo como um processo representacional utilizando-se de imagens, analogias e metáforas, para auxiliar alunos e cientistas a visualizarem e compreenderem um conteúdo, que pode se apresentar de difícil compreensão, complexo e abstrato. Mediante os artigos da área de ensino de Ciências relacionados ao uso da modelização no ensino da Biologia, percebemos que a temática está presente desde o Ensino Fundamental até a formação de professores. Tendo em vista, porém, a natureza dos conhecimentos da Biologia, os modelos constituídos são predominantemente compostos por representações tridimensionais (maquetes) ou por elementos pictóricos (DUSO, 2012).

Krasilchik (2004) destaca que os modelos didáticos são um dos recursos mais utilizados em aulas de Biologia para visualizar objetos de três dimensões. De acordo com Paz et al. (2006), podemos classificar os modelos em três categorias: modelo representacional, conhecido como maquete, que é uma representação física tridimensional (ex. terrário, aquário, estufa, etc.); o modelo imaginário, um conjunto de pressupostos apresentados para descrever um objeto ou sistema (ex. DNA, ligações químicas, etc.), e o modelo teórico, um conjunto de pressupostos explicitados de um objeto ou sistema (ex. sistema solar, ciclo da chuva, ciclo do carbono, etc.).

Sabemos que no ensino de Ciências a utilização de aulas práticas é constantemente mencionada como alternativa para superar a tradição livresca na qual está pautado o ensino de Ciências Naturais no Brasil, tendo em vista que, com esse recurso, o aluno entra em contato com o objeto de estudo e pode se tornar sujeito ativo no processo de aprendizagem (SILVA; PEIXOTO, 2003). Assim, acreditamos no potencial significativo das aulas práticas no processo de construção da aprendizagem, uma vez que pode possibilitar uma formação aos estudantes que passa por experiências que transcendem o campo teórico e despertam nos alunos a curiosidade.

A curiosidade despertada no aprendiz nos remete a inquietações, indagações, como inclinação a novas descobertas. Tal como destaca Freire (1996, p. 32), "não haveria criatividade sem a curiosidade que nos move e que nos põe pacientemente impacientes diante do mundo que não fizemos, acrescentando a ele algo que fazemos". 
Ao estudar o tema a ser investigado por sua classe o professor verifica no conhecimento estabelecido uma rede de ideias implicada no tema em questão e seleciona quais noções pretende desenvolver com seus alunos. As noções escolhidas nortearão o professor na elaboração de problematização às propostas de observação, experimentação e outras estratégias para a busca de informações.

O professor deve ter clareza de que são as teorias científicas que oferecem as referências para que os alunos elaborem suas reinterpretações sobre os temas em estudo, num processo contínuo de confronto entre diferentes ideias. É papel do professor trazer elementos das teorias científicas e outros sistemas explicativos para sua classe sob a forma de perguntas, nomeações, indicações para observação e experimentação, leitura de textos e em seu próprio discurso explicativo (BRASIL, 1998).

Na presente reflexão utilizamos o grilo como a representação dos insetos objetivando diminuir as características repulsivas associadas a esses seres, uma vez que, geralmente, são lembrados como animais que causam doenças ou outros prejuízos, conforme Neto e Pacheco (2008). É quase impossível, no entanto, não conviver de perto com insetos no seio do nosso lar e na escola, campo empírico da nossa experimentação, situado em um espaço denso de vegetação. As formigas habitam nossos jardins e cozinhas; as borboletas, as flores dos canteiros. Estudos comprovam que alguns insetos são nocivos à saúde do homem, no entanto outros exemplares são importantes polinizadores, multiplicadores de sementes e de frutos, por isso a necessidade de conhecer sua biologia (GALLO et al., 2002).

$O$ interesse dos alunos pelos insetos pode ser justificado pelo fato de estes serem extremamente abundantes e diversificados (compreendendo cerca de $75 \%$ das espécies de animais conhecidas), por estarem facilmente presentes no nosso dia a dia e por despertarem grande curiosidade (RUPPERT; FOX; BARNES,2005). Por exemplo, muitas crianças tentam colecionar borboletas, apenas por divertimento, por se encantarem com sua beleza. No que diz respeito à seleção do conteúdo (inseto) por parte dos professores, isso se deve, talvez, aos insetos serem o grupo zoológico que melhor ofereça subsídios para que eles disponibilizem aos seus alunos oportunidades práticas de aprendizagem de conceitos concretos (BIZZO, 2002).

\section{O NOSSO OLHAR SOBRE A APRENDIZAGEM SIGNIFICATIVA: o grilo como modelo de inseto}

A instituição de práticas educativas que permitam o direcionamento do olhar do aluno para os elementos do meio ambiente e para as relações que se estabelecem entre os seres vivos é de fundamental importância para a formação de cidadãos que busquem não só o exercício de seus direitos, como também o entendimento da vida que os cerca, para a utilização adequada dos recursos ambientais (SILVA; CORAZZA, 2011). A criação de insetos em sala de aula é, assim, uma possibilidade que amplia os recursos didáticos disponíveis para o ensino dos conteúdos escolares (SILVA; CORAZZA, 2011). Apesar disso no Brasil a criação de insetos como modelo didático vivo não é uma prática comum. Nesse sentido, a presente pesquisa teve por objetivo apresentar um manual de criação 
de grilos em insetários, de modo que se possa verificar sua aplicabilidade em sala de aula ou laboratório e promover as possibilidades de maior integração entre professor-aluno, tornando a aprendizagem mais significativa no ensino de Ciências.

Pensamos que o educador deve estar embasado teoricamente em amplo conhecimento científico e dispor de metodologias de ensino potencialmente significativas, que possibilitem promover a aprendizagem do aluno, uma vez que "a prática educativa é tudo isso: afetividade, alegria, capacidade cientifica, domínio, técnica a serviço da mudança" (FREIRE, 1996, p. 16).

Acreditamos que o grilo como modelo de inseto potencializa de maneira significativa a prática pedagógica do professor no processo de aprendizagem e consequentemente pode possibilitar ao discente ser sujeito da construção do seu conhecimento. Posição contrária à ideia de restringir o educando ao espelho da educação bancária, espaço da memorização mecanizada, do conteúdo narrado, que torna a educação um "(...) ato de depositar, de transferir, de transmitir valores e conhecimentos"(...) (FREIRE, 1996, p. 67).

Com base em Moreira (2002) compreendemos como uma primeira condição para a construção do significado da aprendizagem é a de que o material a ser apresentado seja potencialmente significativo. Dificilmente o aluno poderá construir significado a partir de materiais vagos. É possível que no caso dos insetos os alunos tenham facilidade de encontrá-los em diferentes ambientes. O grilo, por exemplo, numa rápida observação no contexto da escola (campo empírico do nosso estudo) pode ser coletado com facilidade e oportuniza ao professor estabelecer interação com conceitos e modelos científicos.

Moreira (2011) propõe alguns princípios programáticos facilitadores para potencializar o conteúdo a ser desenvolvido: diferenciação progressiva, na qual as ideias mais gerais e inclusivas da matéria de ensino devem ser apresentadas desde o início da instrução e, progressivamente, diferenciadas em termos de detalhes e especificidades; reconciliação integradora, além da diferenciação progressiva deve explorar as relações entre conceitos e proposições, chamando a atenção para diferenças e semelhanças e reconciliando inconsistências reais e aparentes; organização sequencial, que consiste em sequenciar os tópicos de maneira coerente, estabelecendo relações de dependência existentes entre eles na matéria de ensino; consolidação, que objetiva a aprendizagem significativa, levando a insistir no domínio do que está sendo estudado antes de introduzir-se novos conhecimentos; organizadores prévios, materiais introdutórios apresentados antes do material de aprendizagem em si mesmo, em um nível mais alto de abstração, generalidade e inclusividade, para servir de ponte entre o que o aprendiz já sabe e o que deveria saber para que esse material fosse potencialmente significativo. Eles facilitam a passagem da estrutura conceitual da matéria de ensino para a estrutura cognitiva do aluno de maneira significativa.

O material por si só, no entanto, não é tudo. Uma segunda condição para a construção do significado da aprendizagem está relacionada ao aluno que aprende. Ele deve se predispor a "relacionar interativamente os novos conhecimentos a sua estrutura cognitiva prévia, modificando-a, enriquecendo-a, elaborando-a e dando significados a esses conhecimentos" (MOREIRA, 2002, p. 8). 


\section{OS CAMINHOS PERCORRIDOS PARA O ESTUDO}

O presente estudo teve como campo empírico uma escola pública situada no bairro Nova Olinda, no município de Nilópolis, RJ. Este bairro está localizado na área da antiga Fazenda São Mateus, o que justifica a forte presença de vegetação e consequentemente é comum observar, nas proximidades da escola, grilos, gafanhotos, outros insetos e animais.

Segundo Ausubel et al. (1980), a estrutura cognitiva é constituída pelos conteúdos das ideias e sua organização. A aprendizagem significativa é o processo pelo qual uma nova informação recebida pelo sujeito interage com uma estrutura de conhecimento específica orientada por conceitos relevantes, os conceitos subsunçores - ou conceitos incorporadores, integradores, inseridores, âncoras - determinantes do conhecimento prévio que apoia novas aprendizagens. Moreira (1999) enfatiza que não se trata de simples associação, mas de interação entre os aspectos específicos e relevantes da estrutura cognitiva e as novas informações, por meio da qual essas adquirem significados e são integradas à estrutura cognitiva". Nesse processo, os conceitos subsunçores são reelaborados, tornando-se mais abrangentes e refinados. Consequentemente, são aperfeiçoados os significados e melhorada a sua potencialidade para aprendizagens significativas posteriores.

O universo do presente estudo é formado por 139 discentes com faixa etária entre 13 e 16 anos de quatro turmas do 8o ano. A escolha destes sujeitos foi baseada na Teoria da Aprendizagem Significativa de David Ausubel, ou seja, os conteúdos sobre insetos foram "ancorados" no 7ํano com o apoio da obra de Gewandsznajder (2006) "Ciências: vida na terra", especificamente o capítulo sobre artrópodes. Vale ressaltar que em uma turma, além do livro didático, utilizamos grilos vivos como recurso didático. No processo de desenvolver o conteúdo sobre os insetos, contamos com a colaboração de outros professores da escola.

$O$ instrumento de avaliação dos alunos foi organizado com dez questões sobre o conteúdo desenvolvido. Na $1^{\text {a }}$ questão o aluno deveria assinalar, entre dez animais sugeridos, cinco que compõem o grupo de insetos; na $2^{a}$ questão, identificar o inseto que apresenta metamorfose completa; na $3^{a}$ questão apontar, entre cinco alternativas, como é chamado o tecido que reveste o corpo dos insetos; na $4^{\text {a }}$ questão indicar os insetos que vivem em sociedade; na $5^{\text {a }}$ questão apontar a alternativa que indicava as partes principais do corpo de um inseto; na $6^{\text {a }}$ questão avaliar como o aluno apreendeu a característica dos insetos relacionada à quantidade de pernas necessárias para compor esse grupo; na $7^{a}$ questão o aluno deveria relacionar a convivência e relacionamento entre insetos e seres humanos; a $8^{a}$ questão visava a avaliar como o aluno apreendeu a característica dos insetos relacionada à quantidade de asas da maioria desses indivíduos; a $9^{a}$ questão versava sobre a morfologia do aparelho bucal, relacionando suas estruturas com os tipos de insetos e na $10^{a}$ questão indicar o tipo de respiração que ocorre no grupo dos insetos.

Para a análise dos resultados foi utilizado o Teste do Qui-Quadrado, simbolizado por $\chi^{2}$, desenvolvido por Pearson (RODRIGUES, 2002). Trata-se de um teste de hipóteses que possui o objetivo de encontrar o valor da dispersão para duas variáveis nominais, 
avaliando a associação existente entre variáveis qualitativas. Ele é classificado como um teste não paramétrico porque não depende de parâmetros como média e variância (parâmetros populacionais). O princípio básico deste método visa a comparar as proporções e suas possíveis divergências entre as frequências esperadas $\left(F_{e}\right)$ e frequências observadas $\left(F_{0}\right)$, para um determinado evento.

No nosso caso, as frequências observadas foram obtidas, diretamente, dos dados da amostra. As frequências esperadas foram obtidas da contagem das respostas que esperávamos de acordo com o trabalho de Gil-Pérez et al. (2001). Para nosso estudo existem dois grupos de respostas: aquelas que apresentam ou reforçam as imagens ditas deformadas do trabalho científico, agrupadas nas sete categorias estudadas por Gil-Pérez et al. (2001), e aquelas que não apresentam estas deformações.

Para a aplicação do Teste do Qui-Quadrado, pode-se afirmar que: "se a diferença entre as frequências observadas e esperadas são muito pequenas, próximas a zero, a distorção não está presente".

Na comparação das frequências esperadas e observadas no teste $\chi^{2}$ utilizamos a fórmula:

$$
\chi^{2}=\sum\left(\mathrm{F}_{\mathrm{o}}-\mathrm{F}_{\mathrm{e}}\right)^{2} / \mathrm{F}_{\mathrm{e}}
$$

Para o testes $\chi^{2}$, o pesquisador trabalha com duas hipóteses: aceita-se ou rejeita-se a hipótese nula, dependendo dos valores calculados confrontados com os valores tabelados. As frequências observadas não diferem das frequências esperadas, chamada de hipótese nula, representada por $\mathrm{H}_{0}$. Quando as frequências observadas diferem das frequências esperadas não ocorre associação entre os grupos $\left(H_{1}\right)$.

O procedimento para esta análise depende de duas estatísticas: uma chamada de $\chi^{2}$ calculado - obtida a partir dos dados experimentais, levando-se em consideração os valores observados e esperados relacionados à hipótese; e outra denominada de $\chi^{2}$ tabelado, consultando uma tabela determinada (Tabela de $\chi^{2}$ ), que depende do número de graus de liberdade (GI) e do nível de significância adotado para a análise. O nível de significância representa a máxima probabilidade de erro que se tem ao rejeitar uma hipótese.

Neste caso o grau de liberdade é calculado da seguinte maneira:

$\mathrm{Gl}=$ número de classes -1

Comparando-se os dois valores de $\chi^{2}$, o calculado e o tabelado, toma-se a decisão:

- Rejeita-se $\mathrm{H}_{0}$ : se $\chi^{2}$ calculado > ou $=\chi^{2}$ tabelado. Rejeita-se $\mathrm{H}_{0}$ e aceita-se $\mathrm{H}_{1}$. Os números de frequências observadas e esperadas são estatisticamente diferentes. Os desvios são significativos.

- Aceita-se $\mathrm{H}_{0}$ : se $\chi^{2}$ calculado $<\chi^{2}$ tabelado. Aceita-se a hipótese de igualdade estatística entre os números de frequências observadas e esperadas $\left(H_{0}\right)$. Os desvios não são significativos. 


\section{OS RESULTADOS ENCONTRADOS}

Selecionamos, por turma, duas questões nas quais os alunos encontraram maiores dificuldades em respondê-las. Este foi o critério que estabelecemos para a presente análise. Cabe ressaltar que as dificuldades foram tomadas como forma de repensar e retomar o desenvolvimento do conteúdo, não para constatar se houve ou não aprendizagem, mas como recurso que permita ao aluno refazer as atividades propostas. Também vale lembrar que partimos do pressuposto de que os alunos tinham algum conhecimento sobre os insetos, conteúdo desenvolvido no 70 ano com o apoio da obra de Gewandsznajder (2006) "Ciências: vida na terra", especificamente o capítulo sobre artrópodes.

Conforme explicitado anteriormente, das quatro turmas três trabalharam apenas com o livro didático, ou seja, respectivamente as turmas 801,802 e 803 . Na turma 804 , além do livro didático utilizamos o inseto: grilos, recolhidos no próprio espaço da escola ou residências dos alunos e ainda amostras levadas pelo professor.

Em relação ao uso único do livro didático e do quadro de giz concordamos com Moreira (2011) ao destacar que esses instrumentos simbolizam o ensino transmissível. O livro didático, como observa Rancière (2002), é um instrumento de ensino pronto e acabado, associado ao que se aprende de novo, afinal, tudo está no livro, é como se não houvesse saída para o aluno. Como acrescenta o mesmo autor, "não se sabe que caminho traçará o aluno, mas sabe-se de onde ele não sairá - do exercício de sua liberdade (RANCIÈRE, 2002, p. 35).

O livro didático como único recurso do professor nos remete ao ensino de algumas regras e elementos associados a alguns trechos escolhidos e a alguns exercícios de memorização. Nossa prática nos mostra que precisamos ultrapassar o argumento de muitos colegas professores quando justificam e associam as suas práticas tradicionais às condições materiais das escolas públicas. Queremos ressaltar que a concepção que temos sobre o que seja ensinar e aprender é que nos torna, como professores e alunos, sujeitos ativos ou passivos, afinal como destaca Rancière (2002, p. 37), "quem ensina sem emancipar, embrutece. E quem emancipa não tem que se preocupar com aquilo que o emancipado deve aprender".

Seguem-se os resultados:

Gráfico 1 - Resultados do teste Qui-quadrado

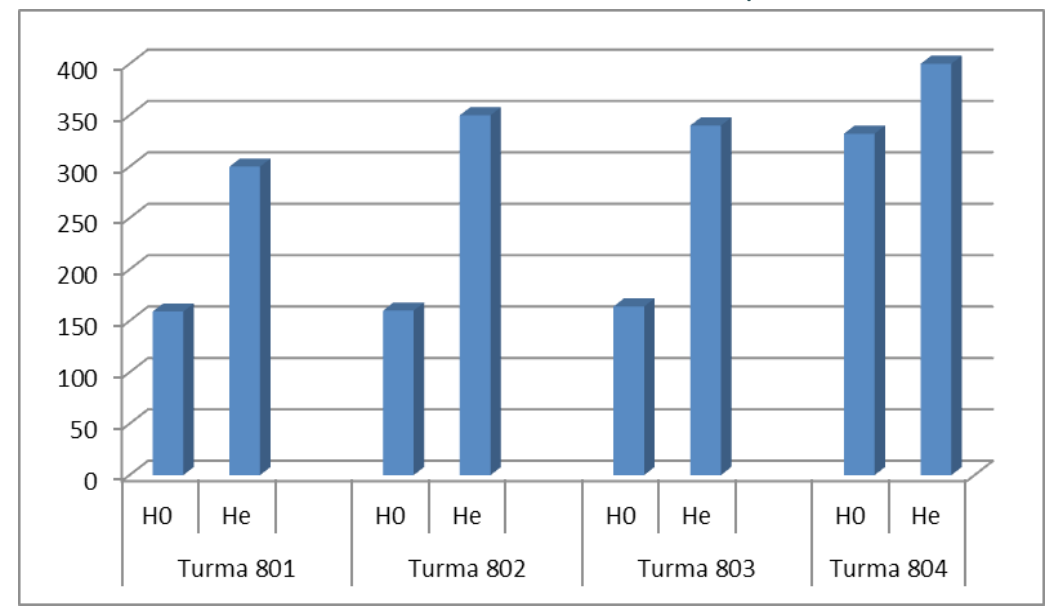

Fonte: Dados da pesquisa. 


\section{Turma 801:}

Para a categoria anteriormente citada, obtivemos os seguintes resultados:

$\mathrm{F}_{\mathrm{e}}=300$

$\mathrm{F}_{0}=159$

$\mathrm{Gl}=29$

$\chi^{2}$ calculado $=66,270$

$\chi^{2}$ tabelado $=42,557$

Rejeita-se $\mathrm{H}_{0}$ ao nível de significância de $5 \%$, há diferença significativa entre a frequência de respostas observadas e esperadas.

Sobre as principais características morfológicas, 26 alunos dos 30 não sabiam que o exoesqueleto é o tecido de revestimento dos insetos, e destes, 21 citaram aranhas e escorpiões como exemplos de insetos. O livro didático como a única estratégia reafirma a concepção mecanicista de ensino no qual basta aos alunos repetirem nos exercícios o que conseguem lembrar para a obtenção de um grau de aprendizagem. Nesse sentido o instrumento avaliativo indicou o que foi possível ao aluno memorizar a partir do conteúdo apresentado no livro didático.

\section{Turma 802:}

Para a categoria anteriormente citada, obtivemos os seguintes resultados:

$$
\begin{aligned}
& \mathrm{F}_{\mathrm{e}}=350 \\
& \mathrm{~F}_{\mathrm{o}}=160 \\
& \mathrm{Gl}=34 \\
& \chi^{2} \text { calculado }=103,142 \\
& \chi^{2} \text { tabelado }=48,602
\end{aligned}
$$

Rejeita-se $\mathrm{H}_{0}$ ao nível de significância de $5 \%$, há diferença significativa entre a frequência de respostas observadas e esperadas.

A maior dificuldade desta turma foi responder sobre a respiração dos insetos. Dos 35 alunos, apenas 2 responderam que a respiração é feita pela traqueia, 82 \% pensam que os insetos possuem dois pares de pernas. A utilização do livro didático como única estratégia para desenvolver um conteúdo pressupõe um tipo de postura diante do que seja ensinar e aprender e consequentemente, postura idêntica ao processo avaliativo. A grande maioria dos livros didáticos não promove a diferenciação progressiva e a reconciliação integradora. A organização desses livros geralmente é linear, iniciando com o mais simples e terminando com o mais complexo. Esse tipo de abordagem nos remete à educação bancária, criticada por Freire (1996), que impossibilita a construção do conhecimento pelo educando e não nos remete à ideia de questionarmos a realidade do aluno.

\section{Turma 803:}

Para a categoria anteriormente citada, obtivemos os seguintes resultados:

$$
F_{e}=340
$$




$$
\begin{aligned}
& \mathrm{F}_{\mathrm{o}}=164 \\
& \mathrm{Gl}=33 \\
& \chi^{2} \text { calculado }=91,105 \\
& \chi^{2} \text { tabelado }=47,400
\end{aligned}
$$

Rejeita-se $\mathrm{H}_{0}$ ao nível de significância de $5 \%$, há diferença significativa entre a frequência de respostas observadas e esperadas.

Dos 35 alunos que compõem este grupo, 35\% obtiveram sucesso na resposta da questão relacionada às principais divisões do corpo de um inseto. Consideramos importante ressaltar que este grupo se destacou na resposta da $7^{a}$ questão (o aluno deveria relacionar a convivência e relacionamento entre insetos e seres humanos) $85 \%$ responderam de forma exata. Levando em conta que o professor utilizou apenas o livro didático como estratégia de ensino, o sucesso dessa última resposta nos remete aos estudos de Moreira (2002) ao apontar como uma das condições para o aluno construir significado é poder relacioná-lo de forma não arbitrária com o que já conhece e inserir nas redes de significados já construídas no decurso de suas experiências prévias de aprendizagem. $\mathrm{O}$ fato de os alunos distinguirem a convivência e relacionamento entre insetos e seres humanos nos remete ao seu próprio dia a dia, quando certamente em sua residência, na escola ou em outros espaços onde vivem há essa convivência com os insetos, de forma harmoniosa ou não.

\section{Turma 804:}

Para a categoria anteriormente citada, obtivemos os seguintes resultados:

$$
\begin{aligned}
& \mathrm{F}_{\mathrm{e}}=400 \\
& \mathrm{~F}_{\mathrm{o}}=332 \\
& \mathrm{Gl}=39 \\
& \chi^{2} \text { calculado }=11,560 \\
& \chi^{2} \text { tabelado }=54,572
\end{aligned}
$$

Aceita-se $\mathrm{H}_{0}$ ao nível de significância de $5 \%$, há diferença significativa entre a frequência de respostas observadas e esperadas.

Nessa turma desenvolvemos as atividades utilizando o livro didático que serviu a todas as outras turmas para apoio e orientação da sequência do conteúdo e também, como estratégia, exemplares do inseto "grilo" coletado em casa, no espaço da escola e alguns apresentados pelo próprio professor. 0 grupo era formado por 40 alunos, dos quais apenas 3 não responderam corretamente que a maioria dos insetos possui dois pares de asas. $O$ resultado parece indicar que houve aprendizagem, a qual nos arriscamos a denominar de significativa a partir do nosso olhar sobre a atividade. Os 3 alunos que não souberam responder nos remetem ao pensamento de Moreira $(2002$, p. 8 ) ao ressaltar que "o significado está nas pessoas, não nos materiais", e que também o "aluno pode querer dar significados aos novos conhecimentos e não ter conhecimentos prévios adequados" (MOREIRA, 2002, p.9). 


\section{CONSIDERAÇÕES FINAIS}

Demo (2005) afirma que não deve haver dificuldades para perceber que o Ensino de Ciências e Biologia precisa oferecer ao discente um desenvolvimento significativo e coerente com o seu cotidiano, ou seja, o que se aprende na escola deve aparecer na vida. Desse modo fica perceptível a necessidade de uma transformação no posicionamento dos docentes no planejamento e elaboração de atividades que influenciem positivamente na aprendizagem e motivem os discentes a assimilarem os conteúdos. 0 aprendizado de Ciências é essencial para que o indivíduo possa analisar crítica e plenamente a realidade do mundo em que vive.

A presente reflexão reafirma nosso pensamento sobre a utilização do livro didático como a única estratégia. Como na experimentação apresentada na Turma 804, a partir de várias espécies de grilos de vários tamanhos sendo observados pelos olhares curiosos dos alunos e no borbulhar dessas observações, há possibilidade de surgirem indagações, comparações e surpresas que não se enquadram em um único livro-texto. O uso do livro didático e do quadro de giz simboliza o ensino transmissível no qual o professor, muitas vezes, "resolve exercícios, para que os alunos copiem na véspera da prova e nela repitam o que conseguem lembrar"“ (MOREIRA, 2011, p. 239).

O fato de ampliarmos o nosso entendimento de que o significado da aprendizagem está no sujeito e não nas estratégias, nos apresenta novas possibilidades para repensarmos os argumentos sobre a falta de equipamentos, laboratórios que circulam no dia a dia da escola pública, como impedimento que possibilita o favorecimento da aprendizagem significativa. Reafirmamos que comungamos com os argumentos dos professores ao exigirem maior investimento na educação pública.

O grilo como modelo de inseto potencializa de maneira significativa a prática pedagógica do professor no processo de aprendizagem e, consequentemente, pode possibilitar ao discente ser sujeito da construção do seu conhecimento. Nesse sentido, a aplicabilidade da presente pesquisa promoveu possibilidades de maior integração entre professor-alunos, tornando a aprendizagem mais significativa no Ensino de Ciências.

Assim, este trabalho contribui para acrescentar novas oportunidades no Ensino de Ciências e Biologia, tornando as aulas mais dinâmicas e aprendizagem significativa mais efetiva.

\section{Referências}

ANTUNES, C. Novas maneiras de ensinar novas formas de aprender. Porto Alegre: Artmed, 2002.

AUSUBEL, D. P. et al. Psicologia educacional. Trad. Eva Nick et al. Rio de Janeiro: Interamericana, 1980.

BIZZO, Nélio. Ciências: fácil ou difícil. São Paulo: Ática, 2002.

BRASIL. Secretaria de Educação Fundamental. Parâmetros Curriculares Nacionais: terceiro e quarto ciclos: apresentação dos temas transversais. Brasília: MEC; SEF, 1998.

BRASIL. Secretaria de educação fundamental. Parâmetros Curriculares Nacionais: Ensino Fundamental e Médio. Brasília: MEC, 1999.

BRASIL. Secretaria de educação fundamental. Parâmetros Curriculares Nacionais. Ensino Fundamental e Médio. Brasília: MEC, 1999.

DE ABREU, R.G. Tecnologia e ensino de ciências: recontextualização no "novo ensino médio". In: Encontro Nacional de Pesquisa em Educação em Ciências - ENPEC, 3., 2001, Atibaia. Anais... Atibaia: Abrapec, 2001a. 1 CD 
DELIZOICOV, D.; ANGOTTI, J. A. Metodologia do Ensino de Ciências. São Paulo: Editora Cortez, 1991.

DEMO, P. Educar pela pesquisa. 7. ed. Campinas: Autores Associados, 2005.

DUSO, L. O uso de modelos no ensino de biologia. ENDIPE - ENCONTRO DE DIDÁTICA E PRÁTICA DE ENSINO, 16., 2012, Campinas. Anais [...]. Campinas, SP: Unicamp, 2012.

FREIRE, Paulo. Pedagogia da autonomia: saberes necessários à prática educativa. São Paulo: Paz e Terra, 1996.

GALLO, D. et al. Manual de entomologia agrícola. São Paulo: Agronômica Ceres, 2002.

GEWANDSZNAJDER, F. Ciências: a vida na Terra. 6a série. São Paulo: Ática, 2006.

GILBERT, J. K.; BOULTER, C. Models and modelling in science education. Reino Unido:, Ed. Springer;, Dordrecht, 1993.

GIL-PÉREZ, D. et al. Para uma imagem não deformada do trabalho científico. Ciência \& Educação, Bauru, 7, (2), p. 125-153, 2001.

KRAPAS, S. et al. Modelos: uma análise de sentidos na literatura de pesquisa em ensino de ciências. Revista Investigação no Ensino de Ciências, Porto Alegre: UFRGS, 1997.

KRASILCHIK, M. Práticas do ensino de biologia. São Paulo: Edusp, 2004.

MATOS, C. H. C. et al. Utilização de modelos didáticos no ensino de entomologia. Revista de Biologia e Ciências da Terra, v. 9, n. 1, 10 Semestre, 2009. ISSN 1519-5228.

MORAES, T. D. S. Estratégias inovadoras no uso de recursos didáticos para o Ensino de Ciências e Biologia. 2016. Dissertação (Mestrado) - Universidade do Estado da Bahia, Salvador, 2016.

MOREIRA, M. A. A Teoria de Ausubel. In: Aprendizagem significativa. Brasília: Editora UnB, 1999.

MOREIRA, M. A. O que é afinal aprendizagem significativa? Aula Inaugural do Programa de Pós-Graduação em Ensino de Ciências Naturais. Instituto de Física. Cuiabá, MT: UFMT, 2002.

MOREIRA, M. A. Teorias de aprendizagem. São Paulo: EPU, 2011.

NETO, E. M. C.; PACHECO, J. M. A construção do domínio etnozoológico "inseto" pelos moradores do povoado de Pedra Branca, Santa Terezinha, Estado da Bahia. Revista Acta Scientiarum - Biological Sciences, v. 26, n. 1, 2008.

PAZ, A. M. da et al. Modelos e modelizações no ensino: um estudo da cadeia alimentar. Revista Ensaio, v. 8, n. 2, 2006.

PREDON, F.; DEL PINO, J. C. Uma análise evolutiva de modelos didáticos associados às concepções didáticas de futuros professores de Química envolvidos em um processo de intervenção formativa. Investigações em Ensino de Ciências, - V14(2), pp. 237-254, 2009.

RANCIÈRE, J. O mestre ignorante: cinco lições sobre a emancipação intelectual. Trad. Lilian do Valle. Belo Horizonte: Autêntica, 2002.

RODRIGUES, P. C. Bioestatística. 3. ed. Rio de Janeiro: EdUFF, 2002.

RUPPERT, E. E.; FOX, R. S.; BARNES, R. D. Zoologia dos invertebrados. 7. ed. São Paulo: Roca, 2005.

SILVA, F. W. O.; PEIXOTO, M. A. N. Os laboratórios de ciências nas escolas estaduais de nível médio de Belo Horizonte. Educação \& Tecnologia, Belo Horizonte, v. 8, n. 1, p. 27-33, 2003.

SILVA, R. R. P. G.; CORAZZA, M. J. O. R. A criação de insetos como recurso didático nas series iniciais do Ensino Fundamental. ENCONTRO DE PRODUÇÃO CIENTÍfICA, 6., 2011, Campo Mourão. Anais [...]. Campo Mourão: Faculdade Estadual de Ciências e Letras, 2011. 